\title{
Usefulness of pulse pressure for the detection of extent and severity of coronary artery disease in type 2 diabetic patients with silent myocardial ischaemia at exercise stress test
}

Received: 2 December 2004 / Accepted: 9 March 2005 / Published online: 4 May 2005

(C) Springer-Verlag 2005

Among diabetic patients with silent myocardial ischaemia (SMI), those showing significant coronary stenosis have the worst prognosis [1]. Although the exercise stress test (EST) is quite well accepted as the first test for the screening of SMI, it is not a predictor of severity and/or extent of ischaemia or of significant coronary artery involvement. Therefore, in patients with SMI, an additional imaging test is undertaken as final proof of ischaemia [2]. The imaging test may also reveal the extent and severity of coronary artery disease (CAD), which allows the early identification of patients for whom revascularisation is appropriate [2].

Together with ST-segment depression, other parameters measured during exercise are evaluated to improve the predictive value for severity of CAD and the risk stratification in non-diabetic and diabetic subjects. Among these parameters, heart rate, with adjustment for ST-segment depression, is the best known [3]. Resting pulse pressure (RPP) is a strong predictor for cardiac events [4]. Increased large artery stiffness, a major determinant of RPP, is frequent in diabetes and may contribute to the development of

\footnotetext{
T. Langialonga $\cdot$ V. Trischitta

Cardiovascular and Endocrine Department,

CSS Scientific Institute,

Viale Cappuccini 1,

71013 San Giovanni Rotondo (FG), Italy

e-mail:dnnwba@tin.it

Tel.: +39-088-2410626

Fax: +39-088-2451637

\section{A. Villella}

Unit of Cardiology ASL-FG/ 3,

F. Lastaria Hospital,

Lucera, Italy

T. Langialonga

Unit of Cardiology, F. Miulli Hospital,

Acquaviva delle Fonti, Italy

V. Trischitta

Department of Clinical Sciences,

University La Sapienza,

Rome, Italy
}

S. Bacci $(\bowtie) \cdot$ M. Villella $\cdot$ A. Villella $\cdot$ A. Rauseo
CAD and ischaemia [5]. However, no data are currently available on the possible diagnostic usefulness of RPP for the detection of CAD in patients with type 2 diabetes.

This cross-sectional study evaluated the usefulness of RPP in predicting severe CAD in patients with type 2 diabetes and SMI.

The study design has been described in detail elsewhere [6]. Briefly, we recruited asymptomatic type 2 diabetic patients, without resting ECG signs of ischaemia, who were considered to be at "high risk" because of peripheral vascular disease (indicated by stenosis $>40 \%$ at ultrasound Doppler) and/or two or more atherogenic factors (family history of myocardial infarction, smoking, urinary albumin excretion rate $>20 \mu \mathrm{g} / \mathrm{min}$, blood pressure $>140 / 90 \mathrm{mmHg}$ or antihypertensive therapy, dyslipidaemia [LDL cholesterol $>3.36 \mathrm{mmol} / \mathrm{L}, \mathrm{HDL}$ cholesterol $<0.90 \mathrm{mmol} / \mathrm{L}$ for men and $<1.16 \mathrm{mmol} / \mathrm{L}$ for women] and triglycerides $>2.26$ $\mathrm{mmol} / \mathrm{L}$ or antidyslipidaemic therapy).

Exclusion criteria were symptoms and/or ECG signs of ischaemia, age above 70 years, claudication below $400 \mathrm{~m}$ and left bundle branch block on resting ECG.

SMI at EST was defined as horizontal or downsloping exercise-induced ST-segment depression being $1 \mathrm{~mm}$ or more at $0.08 \mathrm{~s}$ after $\mathrm{J}$ point, with no angina. CAD was defined as stenosis being $70 \%$ or higher in at least one major epicardial artery at angiography. In accordance with the Helsinki Declaration, all patients were informed about the aim, risks, procedures and possible benefits of the study, and they all gave their consent.

Among the 147 patients included in the study, 114 were EST negative (EST-) and 33 were EST positive (EST+) with asymptomatic ST-segment depression (i.e. had SMI). All 33 EST+ patients underwent coronary angiography. Angiography was also performed in 44 of the 114 ESTpatients; the patients were randomly selected (using a table of random numbers). These patients showed no difference in clinical, metabolic and EST features compared with the 70 EST - patients who did not undergo angiography (data not shown). Twenty-three of the 33 patients with SMI $(\mathrm{EST}+)$ and eight of the 44 patients without SMI (EST-) had CAD. In the ten patients with SMI (EST+) who did 
not have CAD, small vessel disease and/or endothelial dysfunction might be the cause of myocardial hypoxia [7], while the presence of an only moderately reduced flow reserve is likely to explain the absence of ischaemia in the eight EST- patients with CAD [8]. Among patients with SMI, RPP was higher in the 23 with CAD than in the ten without it $(62 \pm 14$ vs $49 \pm 15 \mathrm{mmHg}, p=0.03)$. Diastolic BP $(77 \pm 13$ vs $88 \pm 13 \mathrm{mmHg}, p=0.02)$ but not systolic $\mathrm{BP}(139 \pm$ $17 \mathrm{vs} 138 \pm 21 \mathrm{mmHg}$ ) differed in patients with and without CAD, indicating that the RPP increase observed in the former group was mostly due to a reduction in diastolic BP. In patients with SMI, an RPP of $60 \mathrm{mmHg}$ or higher (median and mean of this group) was associated with CAD in two or more vessels $(n=20$; odds ratio [OR] adjusted for age, sex, duration of diabetes and peripheral vascular disease: 10.9 [95\% CI: $1.1-99.0], p=0.04)$ and in two vessels of the left main coronary artery $(n=14$; OR adjusted for age, sex, duration of diabetes and peripheral vascular disease: 12.9 [95\% CI: $1.5-95.1], p=0.02$ ). Both associations remained significant $(p<0.05)$ after further adjustments for maximal heart rate and heart rate reserve at EST, which are predictors of severe CAD in type 2 diabetic patients with SMI [3].

RPP was not different between the $33 \mathrm{EST}+$ (i.e. with $\mathrm{SMI})$ and the $114 \mathrm{EST}-$ patients $(58 \pm 15$ vs $53 \pm 16 \mathrm{mmHg}$, $p=0.12$ ). In the 44 randomly selected patients who were EST negative and undergoing angiography, while the proportion with peripheral vascular disease and the proportion with a duration of diabetes longer than 10 years were higher in the eight patients with CAD (three with twoand five with one-vessel disease) than in the 36 patients without CAD, no difference in RPP was detected between these two groups $(55 \pm 20$ vs $50 \pm 15 \mathrm{mmHg}, p=0.37)$.

Taken together these data suggest that RPP is only associated with CAD when SMI is also present. Conversely, RPP is not associated with SMI or with CAD when each of these conditions is singly present.
In conclusion, among asymptomatic "high-risk" type 2 diabetic patients with SMI (as detected by EST), RPP seems to be an independent and strong predictor of a more aggressive form of CAD. Further and more detailed studies will clarify whether RPP helps to detect patients who could directly receive angiography treatment for revascularisation with no need for an additional imaging test, thus reducing time and costs for diagnosis and intervention.

\section{References}

1. Cosson E, Guimfack M, Paries J, Payacha F, Attali JR, Valensi P (2003) Prognosis for coronary stenosis in patients with diabetes and silent myocardial ischemia. Diabetes Care 26:1313-1314

2. Stern S (2001) Angina pectoris without chest pain: clinical implication of silent ischemia. Circulation 106:1906-1908

3. Bacci S, Langialonga T, Villella M, Rauseo A, Fanelli R, Trischitta V (2003) Heart rate response during positive exercise stress test predicts coronary artery disease and its severity in high risk type 2 diabetic patients with silent ischemia. Diabetes Care 26:2698-2699

4. Franklin SS, Khan SA, Wong ND, Larson MG, Levy D (1999) Is pulse pressure useful in predicting risk for coronary heart disease? The Framingham Heart Study. Circulation 100:354 360

5. Schram MT, Kostense PJ, Van Dijk RA et al (2002) Diabetes, pulse pressure and cardiovascular mortality: the Hoorn Study. Hypertension 20:1743-1751

6. Bacci S, Villella M, Villella A et al (2002) Screening for silent myocardial ischaemia in type 2 diabetic patients with additional atherogenic risk factors: applicability and accuracy of the exercise stress test. Eur J Endocrinol 147:649-654

7. Nasher P, Brown R, Askarsson H, Winniford M, Rossen J (1995) Maximal coronary reserve and metabolic coronary vasodilatation in patients with diabetes mellitus. Circulation 91:635-640

8. Wilson RF, Marcus ML, Christensen BV, Talman C, White CW (1991) Accuracy of exercise electrocardiography in detecting physiologically significant coronary arterial lesions. Circulation $83: 412-421$ 